\title{
MOBILE BREAKWATERS
}

Chapter 25

MOBILE BREAKWAI'ERS

John H. Carr

Project Engineer, Hydrodynamics Laboratory

California Institute of Technology

Pasadena, California

\section{INIRODUCT ION}

A mobile breakwater may be defined as a structure or device which combines the ability to appreciably reduce the height of ocean waves in its lee with a degree of mobility sufficient to permit its ready transportation for considerable distances and its speedy installation when arrived at the site. Such a device would find application wherever wave protection is necessary for but limited periods, as in offshore drilling operations, or where an installation is required to be completed in a very short time, as in amphibious military operations.

Several attempts have been made in the past to achieve the requirements of a mobile breakwater, some with a fair degree of success. A considerable effort in this direction was expended during World War II, which resulted in the "Phoenix" and "Bombardon" breakwaters used in the Normandy invasion. For the past several years, the Hydraulic Structures Division of the Hydrodynamics Laboratory, California Institute of Technology, has been engaged in a general study of the mobile breakwater problem under the sponsorship of the Bureau of Yards and Docks of the Department of the Navy. This study has resulted in a better understanding of the principles which must govern any mobile breakwater, and has provided the systematic analysis of various projected mobile breakwater schemes.

\section{THEORY OF BREAKWATER ACTION}

The action of any breakwater may be considered in terms of basic wave processes. The theory of breakwater action therefore includes all wave processes which may result in wave height attenuation. The processes of wave refraction, wave interference, wave dissipation, and wave reflection are considered herein. These processes may be briefly described as follows:

Wave refraction is a process resulting from changes in wave velocity, and can result in either an increase or decrease of wave steepness. In the first case, wave breaking with resulting energy loss may occur, and in the second case the desired decrease in wave disturbance is obtained directly. 


\section{COASTAL ENGINEERING}

Wave interference is a process involving the vector addition of the particle velocities of two or more superimposed wave trains. The wave height may be increased or decreased, depending on the direction and phase of the interfering wave trains,

Wave dissipation is the conversion of wave energy into heat energy through the action of frictional forces.

Wave reflection, in the ideal case, is a change in wave direction without energy loss, hence may be likened to perfectly elastic impact. The change in wave direction is determined by the equality of angle of incidence and angle of reflection.

The application of these four processes to the problem of mobile breakwater design will now be considered in more detail.

\section{WAVE REFRACT ION}

Refractive processes are those associated with changes in wave velocity. The familiar case of water wave refraction is that due to changes in bottom topography (Johnson and O'Brien, 1946), the non-uniform depth corresponding to non-unfform wave velocity in the area considered. The basic method of analysis of such problems consists of plotting the position of successive wave crests by consideration of the local wave velocity at each point, followed by construction of orthogonals to the wave crests. The energy transmitted per unit tine, or wave power

$$
P=E C_{g}
$$

is assumed constant between any pair or orthogonals, and by use of this relationship the change in wave helght may be determined. It is obvious that diverging orthogonals, corresponding to submarine canyons, are associated with wave height attenuation. Conversely, converging orthogonals, corresponding to submarine ridges, are assoclated with wave height amplification. It may be noted that where favorable bottom topography fortuitously occurs at a chosen operational site, a certain amount of "breakwater" action will be obtained from the natural wave refraction phenomena. However, the large scale of topographic irregularity necessary for appreciable wave height attenuation precludes the use of artificially created topographic conditions as a mobile breakwater.

Another case of wave refraction occurs when waves advance into a region where a current exists. In this case, the wave velocity with respect to a fixed frame of reference is equal to the vector sum of the wave velocity with respect to the water and of the water velocity (current) with respect to the fixed frame of reference. The analysis of this problem follows the same method as that for the case of velocity change due to changing water depth. 


\section{MOBILE BREAKWATERS}

For the case of an opposing current and deep-water waves, an analytic expression for the change in wave steepness can be obtained. This result, as show in Fig.1, shows that an opposing current of velocity one-fourth the wave velocity will oause a deep-water wave of any initial steopness to build up a steepness of $1 / 7$ and so presumably break and dissipate its energy (Scripps Institution of Dceanography, 1944). Such a current could be considered a mobile breakwater.

It may be pointed out that whereas a current of 10 to $12 \mathrm{ft} / \mathrm{sec}$. which might be considered barely feasible of attainment - would provide effective breakwater action, this is only true for deep-water waves, and it is unlikely that breakwater protection would be desired so far of eshore as to insure deep-water wave conditions.

A more complete analysis, not restricted to deep-rater waves yields a transoendental equation for the change in wave length (Carr, 1950):

$$
L_{0}=\frac{\sqrt{9 d}}{C_{0}} \sqrt{\frac{\tanh \frac{2 \pi d}{L}}{L}}+\frac{V}{C_{0}}
$$

where the subscript 0 refers to initial conditions outside the current zone and $\mathrm{V}$ is the ourrent velocity.

This equation can be solved by trial, Fig.2, for given initial conditions and the wave length $L$ and group velocity $\mathrm{Cg}$ of the refracted waves so determined. The change in wave steepness can then be computed:

$$
\frac{H}{L} / \frac{H_{0}}{L_{0}}=\sqrt{\frac{C_{90}}{C_{9}}} \frac{L_{0}}{L}
$$

It can be shown that in this case a current of any velocity will only cause waves to reach a steepness ratio of $1 / 7$ if the initial steepness is greater than some minimum. However, for any initial conditions, there always exists a critical current velocity for which no waves can traverse the current zone. From basic energy considerations, this current value is:

$$
V=-\operatorname{Cg}
$$

and this result can also be derived from Eq.2.

As a numerical example, it may be pointed out that the current velocity required to prevent transmission of 10-sec. waves in a water depth of 50 foet is about $25 \mathrm{ft} / \mathrm{sec}$., and such a high velocity current is surely impractical. 
WAVE INRERERENCE

A progressive wave train traveling in the $x$-positive direction may be represented by the equation for the surface elevation at any point $x$ and time $t$ :

$$
y_{1}=\frac{H}{2} \sin 2 \pi\left(\frac{t}{T}-\frac{x}{L}\right)
$$

If a second wave train of identical period and amplitude, but with phase difference $\varnothing$ travels in the same direction, it 6 surface elevation is:

$$
y_{2}=\frac{H}{2} \sin \left[2 \pi\left(\frac{t}{T}-\frac{x}{L}\right)+\phi\right]
$$

and the net motion becomes:

$$
y=y_{1}+y_{2}=\frac{H}{2} \sqrt{2(1+\cos \phi)} \sin \left[2 \pi\left(\frac{t}{T}-\frac{x}{L}\right)+\alpha\right](7)
$$

Thus, the resultant wave height will vary from twice the original down to zero as the phase difference varies from zero to $180^{\circ}$ (one-half wave length).

This principle of wave interference could be applied as a mobile breakwater if some means could be devised for producing the secondary wave.

Interference can also be considered as oceurring when waves advance into a region characterized by a vertically stratified current. Thus, if a current exists in a surface layer, the wave motion in this layer will be advanced or retarded with respect to the wave motion in the undisturbed deeper regions, and destructive interference can occur. It has been shown by G.I. Taylor (1943) that this mechanism is responsible for the (Iimited) performance of the pneumatic breakwater, a device often proposed as a mobile breakwater. Because of its prominence in the literature, this device will be described in some detail at this point.

\section{Preumatic Breakwater}

The pneumatic breakwater, as conceived by Philip Brasher and patented by him in 1907, 1921, and 1929, consists of a submerged pipeline containing spaced discharge holes and supplied with compressed air from a ship or the shore. The resulting screen of rising air bubbles is claimed to prevent the passage of incident wave trains.

Although at no time did the inventor advance any sound analytic basis for the claimed performance, he was successful in obtaining several 


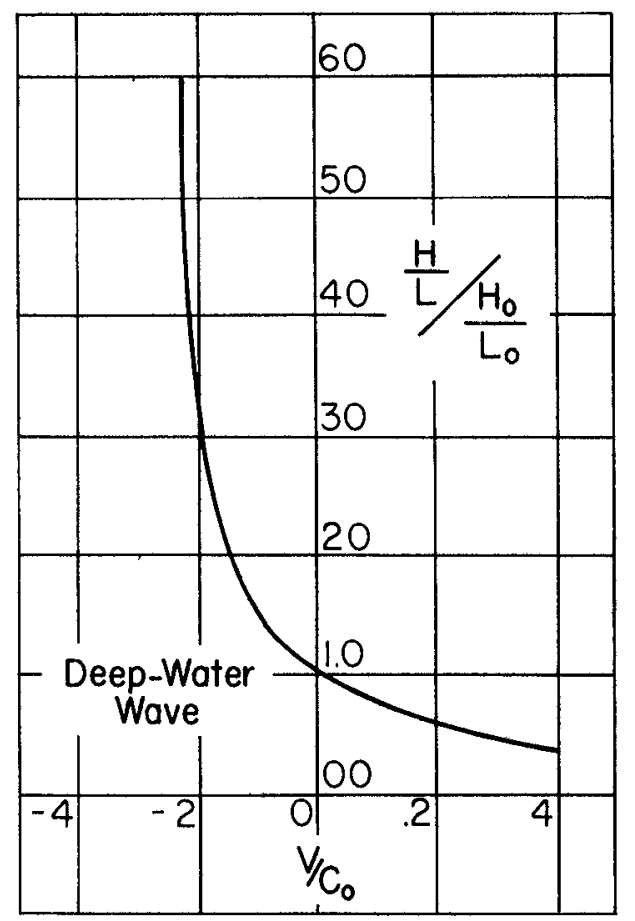

Fig. 1. Change in deep-water wave steopness due to refraction by a uniform current of velocity $v$.

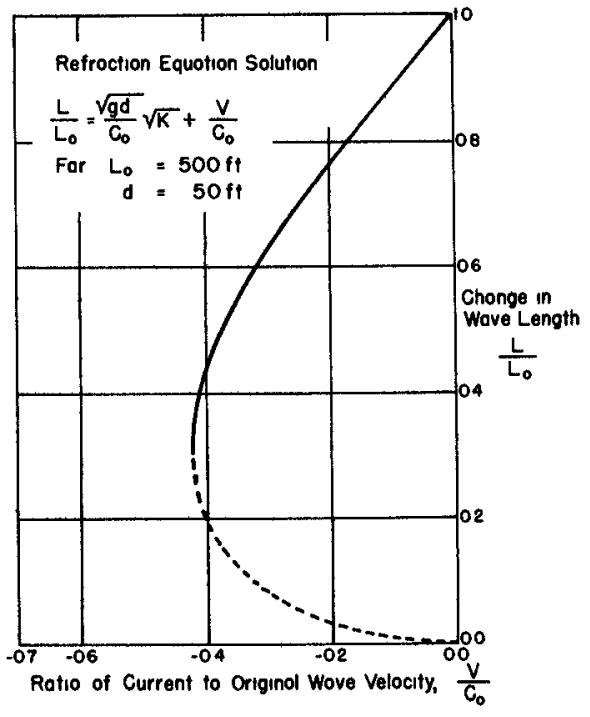

Fig. 2. Graphical representation of the general equation for wave refraction by a uniform current.
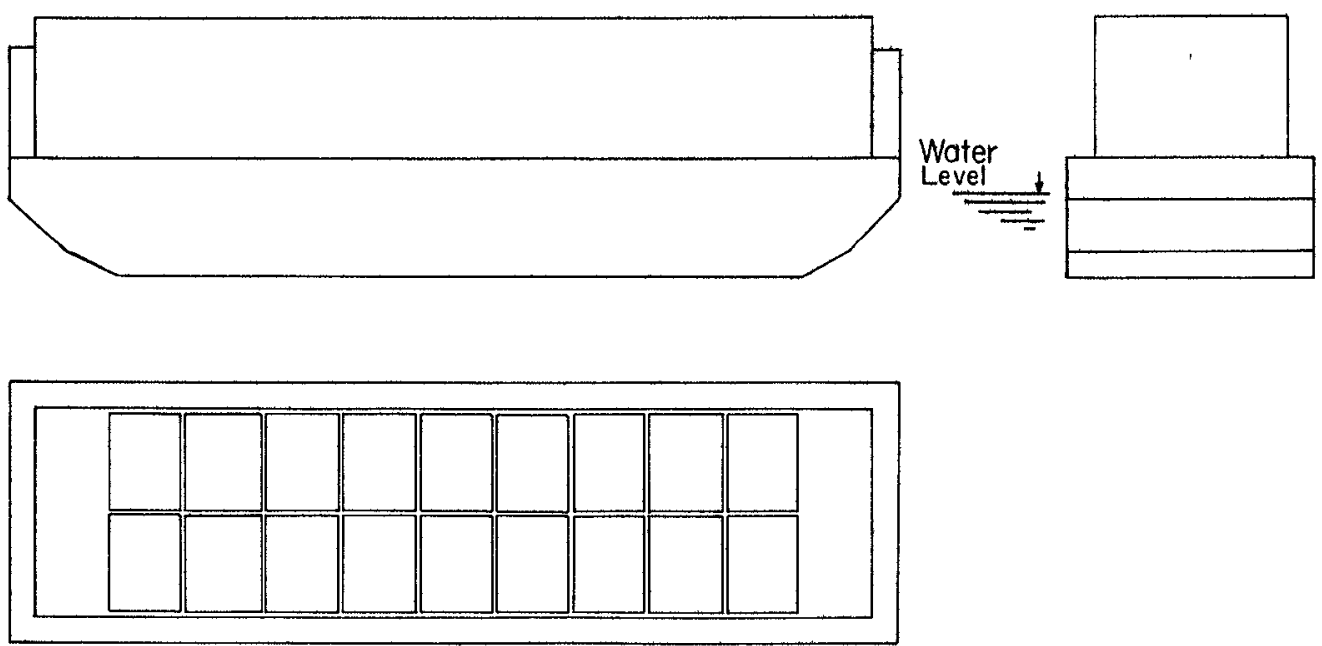

Fig. 3. Diagramatic sketch of the "Phoenix" breakwater.

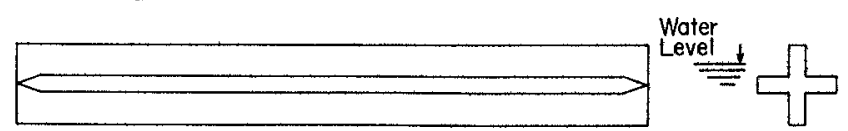

Fig. 4. Diagramatic sketch of the "Bombardon" floating breakwater. 


\section{COASTAL ENGINEERING}

full-scale trials of his device in the period 1907-1929. One of the most extensive trials was at the Standard Oil Co. pier at El Segundo, California; but the results on this occesion, as on the others are not clear, there being a wide disagreement between inventor and client as to the value demonstrated. At any rate, at no time was a trial installation made permanent.

When plans were first being made for the invagion of Europe, the pneumatic breakwater was one breakwater device considered. Model studies performed by the British in 1942 were the basis of the first careful analysis of the mechanics of the pneumatic breakwater and showed the severe limitations of its usefulness. These experiments proved that any wave suppressing action of the air breakwater is due to the upward water current induced by the rising bubbles, and that duplicate results could be obtained when the water current is produced by any means, such as jets or propellors.

In 1943, G.I. Taylor made a complete analysis of the problem and derived a relationship between the length of wave which can be damped and the magnitude of the horizontal surface current resulting from the vertical current induced by the bubble screen. Calculations based on Taylor's theory show that the current required to damp very short period waves to be moderate and conceivably practical of generation by means of an air bubble screen, but for wave lengths or periods of the order to be expected in typical coastal environments the current values and corresponding power requirements to generate these currents become enormous.

\section{WAVE DISSIPAT ION}

Wave energy can be dissipated in the form of heat through the mechanism of fluid turbulence. For the dissipation to proceed at a high level, the turbulence must be general and violent; this is the wave breaking process.

Wave breaking occurs naturally on shelving coasts, where most windgenerated wave energy is finally dissipated. The process of wave breaking on such shorelines is preceeded by the increase of wave steepness (due to shoaling) to the point of instability.

It is obvious that artificial offshore bars or reefs for the purpose of inducing wave breaking are a very limited form of mobile or artificial breakwater. Another possibility for inducing wave breaking is a submerged vertical barrier that comes close to the still water level. It has been shown that such barriers can induce wave breaking under some conditions (Worison, 1949) (where the wave is already near the condition of instability). However, such a barrier is also a fairly efficient reflector and as such must be designed to withstand rather large forces. 
WAVE REFLECIION

A fixed vertical barrier projecting above the water surface produces 100\% reflection of incident waves. Thus, for normal incidence, the amplitude of the reflected wave train, $\mathrm{Hr} / 2$, is equal to the amplitude of the incident wave train, $\mathrm{Hi} / 2$, and at the barrier the variation of the water level with respect to time becomes $H_{i} \sin 2 \pi t / T$.

An important consideration in the reflection process is the question of the magnitude of the forces acting on the reflecting berrier. These forces can be computed in terms of the wave heights by use of several formulas, such as that due to Sainflou, but in the present case a simpler scheme will be used.

For shallow-water wave conditions, which may be expected to be nearly the case for the water depths in which breakwaters are to be used, the pressure distribution below the surface is very nearly hydrostatic, hence the force on a barrier with mean water depth $d$ and with the assumption of sinusoidal waves becomes:

$$
F=\frac{1}{2} w\left(d+H_{i} \sin 2 \pi \frac{t}{T}\right)^{2}-\frac{1}{2} w d^{2}
$$

or, neglecting the $H_{i}^{2}$ term,

$$
F=w d H_{i} \sin 2 \pi \frac{t}{T}
$$

For a submerged vertical barrier, the weve system includes the incident and reflected waves:

$$
\begin{aligned}
& \frac{H i}{2} \sin 2 \pi\left(\frac{t}{T}-\frac{x}{L}\right) \\
& \frac{H r}{2} \sin 2 \pi\left(\frac{t}{T}+\frac{x}{L}\right)
\end{aligned}
$$

and the transmitted wave:

$$
\frac{H_{t}}{2} \sin 2 \pi\left(\frac{t}{T}-\frac{x}{L}\right)
$$

The phase relationships between these waves at the plane of the barrier can be determined by use of the requirements of conservation of energy:

$$
H_{i}^{2}=H_{r}^{2}+H_{t}^{2}
$$


and continuity, which requires the horizontal particle velocity to be continuous across the plane of the barrier. On this basis, the differential water surface elevation across the plane of the barrier is:

$$
H_{r} \sin 2 \pi\left(\frac{t}{T}+\alpha\right)
$$

Thus, if a submerged barrier is of sufficient height to produce appreciable wave reflection, it will be subjected to horizontal forces comparable in magnitude to those computed for the preceeding case.

\section{APPLICATIONS OF WAVE REFLECTION}

There are in general two methods by which the forces acting on a mobile reflecting barrier could be resisted. In the first case, the barrier could be designed as a grevity dam, with sufficient mass and base width to prevent overturning, and in the second case the barrier could be restrained by a mooring system, with anchors or pilings as the resisting elements. It is interesting that both of these design approaches were developed in full size units for the Normandy invasion of World War II. The following brief descriftion and history of these developments gives some idea of what is required of a mobile breakwater in the form of a fixed reflecting barrier.

\section{PHOENIX}

The principal wave protection at the Normandy invasion harbors was afforded by breakwaters constructed of block ships and special reinforced concrete caisson structures called "Phoenix" (Wood, 1948). The design of the Phoenix units was governed by the following set of conditions:

(1) Maximum tidal range 22 feet.

(2) Theoretical trochoidal waves 8 feet high and 120 feet wave length.

(3) Hinimum freeboard when sunk, 6 feet.

(4) To be capable of being towed at $4 \frac{1}{2}$ knots in a force 4 wind by a 1000 horsepower tug.

The resultant design was an open-top cellular caisson, with one longitudinal dividing wall and ten crosewalls, as shown in Fig.3. The units were all approximately 204 feet in length and varied in depth from 35 to 60 feet and in width from 44 to 62 feet, the variation in the latter dimensions being in accordance with the water depth in which the individual units were to be sunk. The design included scow-shaped ende to achieve the required towing condition.

Construction of 147 of these units, sufficient for six miles of breakwater, was completed in 150 days, utilizing several dozen building sites and a labor force in excess of 20,000 . The units were for the most 
part butlt in graving docks, although twenty-four of the smaller units were built on ways and side-launched.

The units were successfully towed to the two invasion harbor sites, St. Laurent (American) and Arromanches (British), the first units arriving on $D+1$. At Arromanches, 15 blockships and 7 Phoenix units were in place by $D+4$, an additional 12 Phoenix units by $D+9$, and 6 more by $D+12$. During this same period, substantial numbers of caissons were also successfully placed at the American harbor. The time required to position a caisson and complete its sinking was of the order of 90 minutes, of which about 16 minutes was required for the actual flooding and sinking process.

The breakwaters formed by the rows of Phoenix units completely fulfilled expectations until the storm of June $19-22$, 1944. This storm, which produced wave heights up to 12 feet and lengths up to 350 feet off the invasion coast, resulted in virtually complete destruction of the breakwater at St. Laurent. At Arromanches, an out-lying reef partially protected the artificial harbor and only five of the caisson units were destroyed. As a result of the storm damage, the St. Laurent site was abandoned and further harbor development work concentrated at Arromanches. By $D+44,38$ additional caissons were installed at Arromanches, 20 more by $D+71,16$ more by $D+119$, and 14 more by $D+149$. Most of units installed subsequent to $D+44$ were for the purpose of repairing damage and preparing for winter storms by placing calsson units to seaward of the original line of block ships.

Failure in the original Phoenix design was due to two causes; excessive internal pressure when overtopped by large waves and excessive hogging moments induced by scour of the sea bed material at the scowshaped ends of the caissons. The design of the caissons used in the later stages of the harbor construction was modified to include a complete reinforced concrete deck, which both prevented excessive flooding of the interior and provided much greater resistance to hogging. Many of these improved units were still sound several years after the War, and were raised and towed to Sweden for use in the construction of an oil dock in Stockholm harbor.

\section{BOMBARDON}

The design and construction of Phoenix was primarily the responsibility of the Royal Engineers. A parallel, and in a sense competing program, "Bombardon" was carried out at the same time by the Royal Navy. (Lockner, Faher and Penney, 1948).

Bombardon was designed as a floating vertical wave reflector, projecting far enough below the surface to intercept most of the incident wave energy and remaining fixed in position by a combination of its 


\section{COASTAL ENGINEERING}

dynamic characteristics and a mooring system. The units were constructed of $1 / 4$ inch steel plate in 200-foot long units, each unit weighing approximately 250 tons. In section the units were cross-shaped with approximate depth and beam of 25 feet and draft of 19 feet, as shown in Fig.4. The horizontal arm of the cross was submerged so the beam at the water line was but 5 feet.

The cross-section was so designed to combine large mass (including the mass of water compelled to move with the hull) and small restoring force (due to the small waterline cross-section), and thus have rolling, pitching, and heaving periods long compared with the expected wave periods. By this means it was expected that the units would execute only small vertical and rolling motions when exposed to wave conditions. The units ware designed to be moored in line with seaward and leeward anchors with a gap of 50 feet between the units. The units were connected to each other with twin 18-inch manila rope strops. In order to further reduce the wave energy whish would be transmitted through the gaps, it was planned to use two parallel rows with staggered gaps.

Test sections of such a breakwater were constructed and installed in Neymouth Bay by early April 1944. These-trials proved the units to be very successful for the design conditions, typical results being the reduction to 2 feet height of waves estimated to be 8 feet high and 170 feet wave length, incident on the breakwater.

One mile of Bombardon breakwater, installed in a single line, were installed at both invasion harbors by $D+6$. The breakwaters were observed to perform as expected, reducing wave heights in their lee by about $50 \%$, which is equivalent to an energy reduction of $75 \%$. The Bombardon units withstood the first 30 hours of the storm of June 19 23, but eventually were completely destroyed. If may be noted that not only were the mooring stresses imposed by the storm waves greatly in excess of the design conditions, but that the longer periods of the storm waves approached the resonant periods of rolling and heaving of the floating structures, thus producing large amplitude motions in these modes.

\section{REFLECT ING BARRIER WITH MOTION}

The reflecting barriers previously considered are designed to be fixed in space, and must therefore develop reactions sufficient to oppose the wave pressures developed by the reflection process. An interesting theoretical possibility is a barrier which is permitted some horizontal oscillating motion. Such a barrier cannot develop total wave reflection, but can produce appreciable reflection, hence permit tolerably small wave transmission. An important corollary of the barrier's motion is that the required mooring force may be appreciably reduced. 
The limiting case for such a barrier is that of no restraint, in which case the motion of the barrier of weight $W$ is described by the equation of dynamics:

$$
\frac{W}{g} \ddot{x}=F(t)
$$

where

$$
F(t)=w d\left(y_{1}-y_{2}\right)
$$

and

$$
\begin{aligned}
& y_{1}=\frac{H_{i}}{2} \sin 2 \pi \frac{t}{T}+\frac{H r}{2} \sin \left(2 \pi \frac{t}{T}+\alpha\right) \\
& y_{2}=\frac{H_{t}}{2} \sin \left(2 \pi \frac{t}{T}-\beta\right) \\
& W=\text { specific weight of seawater. } \\
& Y_{1}=\quad \begin{array}{l}
\text { water surface elevation measured from still } \\
\text { water surface at seaward face of barrier. }
\end{array} \\
& y_{2}=\text { as } Y_{1} \text {, at leewara face of barrier. }
\end{aligned}
$$

$H_{i}, H_{r}, H_{t}=$ incident, reflected and transmitted wave heights. $\alpha, \beta=\begin{aligned} & \text { arbitrary phase angles to be determined from the } \\ & \text { continuity requirementa. }\end{aligned}$

The solution of this equation gives:

Transmission coefficient, $C_{t}=\frac{H_{t}}{H_{i}}=\frac{1}{\sqrt{1+\left(\frac{\pi W}{W L \cdot d}\right)^{2}}}$

Reflection coefficient, $C_{r}=\frac{H_{r}}{H_{i}}=\frac{1}{\sqrt{1+\left(\frac{w L d}{\pi V}\right)^{2}}}$

The relationship between transmission coefficient, $C_{t}$ and the parameter $W / w L d$, which is the ratio of barrier weight per unit width to weight of sea water per wave length per unit width is plotted in Fig. 5 .

With the provision for some restraint in the form of an elastic mooring of spring constant $K$, the dymamic equation becomes: 
COASTAL ENGINEERING

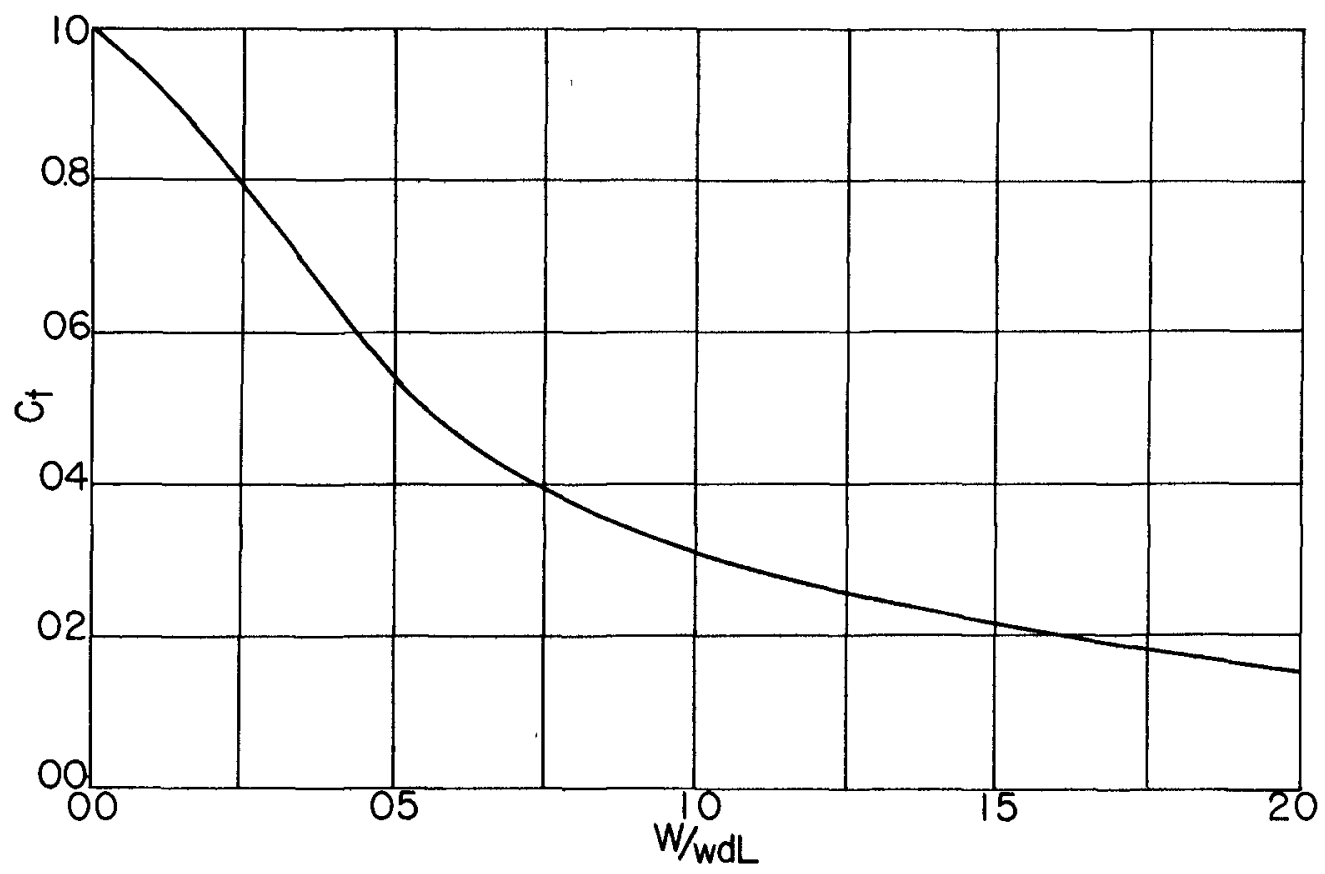

Fig. 5.

Theoretical transmission coefficient as a function of W/wLd for a freoly floating (no horizontal restraint) barrier.

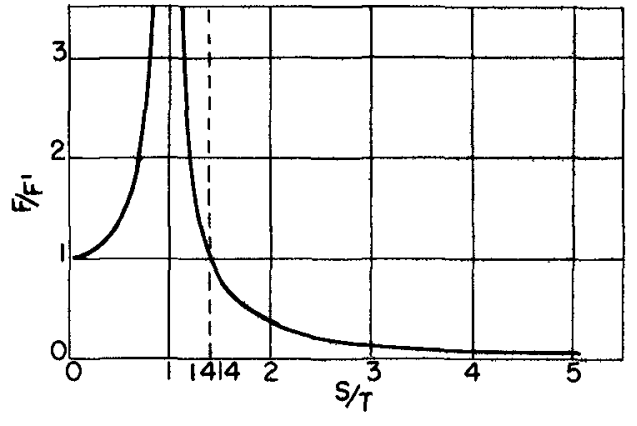

Fit. 6.

Ratio of maximum mooring forces for elastically and rigidly moored barriers as a function of $\mathrm{s} / \mathrm{T}$.

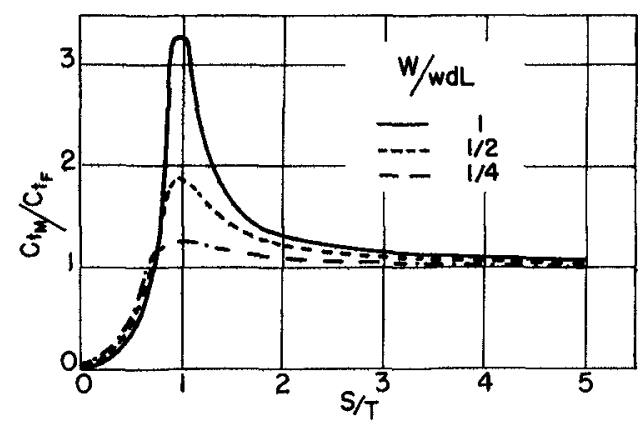

Fig. 7.

Ratio of transmission coofficients for elastically and freely moored barriers as a function of $\mathrm{S} / \mathrm{T}$. 


$$
\frac{W}{g} \ddot{x}+K x=F(t)
$$

and

$$
C_{t}=\frac{1}{\sqrt{1+\left(\frac{\pi W}{W L d}\right)^{2}\left(\frac{1}{\left(\frac{s}{T}\right)^{2}}-1\right)^{2}}}
$$

where $S=$ natural period of barrier mass - mooring spring syatem

$$
=\frac{2 \pi}{\sqrt{\frac{k g}{W}}}
$$

The maximum force per foot of breakwater length becomes:

$$
F_{\text {max }}=\frac{w d H_{r}}{1-\left(\frac{s}{T}\right)^{2}}
$$

It may be noted that the corresponding maximum force on a rigidly fixed barrier is

$$
F_{\text {MAX }}^{\prime}=w d H r
$$

$$
\text { hence } \frac{F_{\text {MAX }}}{F_{\text {MAX }}^{\prime}}=\left|\frac{1}{1-\left(\frac{S}{T}\right)^{2}}\right|
$$

This relationship is plotted in Fig.6.

The effectiveness of the partially restrained barrier may be conveniently expressed as a ratio to that of the completely free barrier:

$$
\frac{C_{t \text { MOORED }}}{C_{t \text { FREE }}}=\sqrt{\frac{1+\left(\frac{\pi W}{W L d}\right)^{2}}{1+\left(\frac{\pi W}{W L d}\right)^{2}\left(\frac{1}{\left(\frac{s}{T}\right)^{2}}-1\right)^{2}}}
$$

This relationship is plotted in Fig.7 for several values of the parameter W/wLd. 


\section{COASTAL ENGINEERING}

From the plots of Figures 6 and 7 it is seen that for values of $S / T$ greater than about 2 , the mooring force is greatly reduced from that required of a fixed barrier, while the coefficient of transmission is increased very little over that of a completely free barrier.

\section{FUTURE DEVELOPMENTS}

It is anticipated that further development of mobile breakwaters will make use of wave reflection as the principal basis of operation. It also seems clear that the problem most in need of solution is that of providing resistance to the wave pressures inherent in the reflection process.

If mobile reflecting barriexs may be divided into two broad classes, floating and fixed, it is further suggested that floating barriers, as typified by Bombardon, deserve more intensive development. The advantages of a floating system over a gravity system are many, chief among which may be listed:

(1) Economy of material.

(2) Freedom from foundation problems.

(3) Freedom from erosion problems.

(4) Indifference to tidal changes in site water depth.

(5) Probable relative ease of transportation.

In the future development of moored floating barriers, two specific objectives may be listed:

(1) Hydrodynamic design of the hull to obtain very long natural periods of rolling, pitching, and heaving.

(2) Design of mooring systems, particularly the anchor points, to obtain greater ultimate strengths.

Any development program on floating barrier should also investigate more thoroughly the practical possibilities of free or elastically-restrained barriers of large mass.

\section{REFERENCES}

Carr, J. H. (1950). Mobile Breakwater Studies:

Hydrodynamics Laboratory Report No. N-64.2, California Institute of Technology, Pasadena, California.

Johnson, J. W. and O'Brien, M. P. (1946). Graphical Construction of Wave Refraction Diagrams: Technical Report its-116-221, University of California, Berkeley, California. (Unpublished)

Lochner, R., Faher, O., and Penney, W. (1948). The Bombardon Floating Breakwater: The Civil Engineer in War, Vol. II, Institute of Civil Engineers, London. 


\section{MOBILE BREAKWATERS}

Morison, J. R. (1949). Model Study of Vave Action on

Underwater Barriers: Report No. HE-I16-304,

University of Callfornia, Berkeley, California. (Unpublished)

Scripps Institution of Oceanography (1944). On Wave Heights in Straits or Sounds where Incoming Waves Meet a Strong Iidal Current: Wave Report No.11, La Jolla, California. (Unpublished)

Taylor, G. I. (1943). Note on the Possibility of Stopping Sea Waves by Means of a Curtain of Bubbles: British Admiralty Report ATR/MISC 1259.

Wood, C.J.R. (1948). Phoenix:

The Civil Engineer in War, Vol. II

Institute of Civil Engineers, London. 